\title{
PERMEANDO A PEÇA LE CIRCO DE LA DRAG: resistência aos tempos de ódio e ressentimento no contexto brasileiro
}

\author{
PERMEATING THE SPECTACLE LE CIRCO DE LA DRAG: resistance to \\ times of hatred and resentment in the Brazilian context
}

\section{PERMEANDO LA OBRA LE CIRCO DE LA DRAG: resistencia a tiempos de odio y resentimiento en el contexto brasileño}

\begin{abstract}
Alexsandro Rodrigues ${ }^{1}$ \& Lívia Rocha Helmer ${ }^{2}$
RESUMO: Este artigo se colocou em conversas com a peça Le Circo de La Drag, sua produção aconteceu no sexto capítulo da dissertação intitulada Quem vê close - Não vê corre: Porosidade de um corpo em viagens com Drag Queens. Nesta dissertação a viajante-pesquisadora habitou com seus amigos-viajantes eventos com protagonismo de drag queens. Neste texto a peça analisada foi encenada durante as eleições presidenciais do Brasil, caracterizada por polarizações políticas e notícias falsas. Diante deste cenário a peça se organizou como sátira política com quatro drags parodiando os últimos acontecimentos do país. O espetáculo tinha como "enredo" músicas brasileiras consagradas e cada música foi problematizada e parodiada nas atuações das drags. O espetáculo criticava a naturalização das músicas que remetiam a violência de gênero, racial entre outras. A proposta da peça foi suscitar reflexões sobre os contextos nos quais estamos inseridos e como autorizamos e naturalizamos práticas de violência e ódio.
\end{abstract}

Palavras-chaves: Espetáculo, drags e viagem.

1 Alexsandro Rodrigues é Professor do Centro de Educação e do Programa de Pós-Graduação em Psicologia Institucional da Universidade Federal do Espírito Santo. Coordenador do Núcleo de Estudos de Pesquisa em Sexualidade (NEPS/UFES). xela_alex@bol.com.br.

2 Lívia Rocha Helmer é Mestra em Psicologia Institucional da Universidade Federal do Espírito Santo - UFES. livia.helmer@ hotmail.com. 


\begin{abstract}
This article was placed in conversations with the play Le Circo de La Drag, its production took place in the sixth chapter of the dissertation entitled Who sees close - Does not see runs: Porosity of a body in trips with Drag Queens. In this dissertation, the traveler-researcher lived with her drag-queens with her traveling friends. In this text, the analyzed play was performed during Brazil's presidential elections, characterized by political polarizations and false news. Given this scenario, the play was organized as political satire with four drags parodying the latest events in the country. The show had as a "plot" consecrated Brazilian songs and each song was problematized and parodied in the drags' performances. The show criticized the naturalization of songs that referred to gender, racial and other violence. The purpose of the play was to raise reflections on the contexts in which we are inserted and how we authorize and naturalize practices of violence and hatred.
\end{abstract}

Keywords: Show, drags and travel.

ABSTRACTO: Este artículo se colocó en conversaciones con la obra de teatro Le Circo de La Drag, su producción tuvo lugar en el sexto capítulo de la disertación titulada Quién ve de cerca No ve corre: Porosidad de un cuerpo en viajes con Drag Queens. En esta disertación, la viajerainvestigadora convivía con sus drag-queens con sus amigas viajeras. En este texto, la obra analizada se realizó durante las elecciones presidenciales de Brasil, caracterizadas por polarizaciones políticas y noticias falsas. Ante este escenario, la obra se organizó como una sátira política con cuatro drags parodiando los últimos acontecimientos del país. El espectáculo tuvo como "trama" canciones brasileñas consagradas y cada canción fue problematizada y parodiada en las actuaciones de los drags. El programa criticó la naturalización de canciones que se referían a la violencia de género, racial y de otro tipo. El propósito de la obra fue plantear reflexiones sobre los contextos en los que estamos insertos y cómo autorizamos y naturalizamos prácticas de violencia y odio.

Palabras clave: Espectáculo, arrastre y viaje.

Nesta aventura em viagem pelo meio, somos transladados a experimentar o mundo do teatro por intermédio da peça "Le Circo de La Drag"3. Este espetáculo

\footnotetext{
3 "Le Circo de la Drag" é um coletivo de artistas de diferentes locais do Brasil que residem na cidade do Rio de Janeiro e, atualmente, circulam com o espetáculo homônimo. O grupo é formado por Juracy de Oliveira, Leonardo Paixão, Mateus Muniz e Vanessa Garcia. Fonte: <https://prosas.com.br/empreendedores/18463 > Acesso em: 8 maio 2020.
} 
foi responsável pela abertura do Festival Nacional de Teatro de Vitória, e a apresentação desta peça aconteceu no dia 15 de Outubro de 2018 no Teatro Carlos Gomes. A peça contou com lotação máxima do teatro e foi encenada em data próxima do segundo turno das eleições presidenciais do Brasil. Nesta época, o contexto brasileiro era permeado por polarizações políticas e notícias falsas (fake news $)^{4}$. Diante deste cenário, a peça se organizou como sátira política com quatro drags parodiando os últimos acontecimentos políticos do país.

O espetáculo tinha como "enredo" músicas brasileiras consagradas. Cada música escolhida foi problematizada e parodiada nas atuações das drags. Temas como racismo, corrupção, machismo, LGBTfobia, entre outras pautas, foram apresentados, criticando a naturalização das músicas que remetiam à violência contra mulher, à propagação de práticas racistas e a discursos homofóbicos. A proposta da peça foi suscitar reflexões sobre os contextos nos quais estamos inseridos e como autorizamos e naturalizamos práticas de violência e ódio.

Quando falamos de violência nos remetemos ao viajante Luis Antônio Baptista (1999, p. 46) e seu célebre texto "A Atriz, o Padre e a Psicanalista - os Amoladores de Facas". Nesse texto, Baptista nos fala que "os amoladores de facas, à semelhança dos cortadores de membros, fragmentam a violência da cotidianidade, remetendo-a a particularidades, a casos individuais". De acordo com o texto de Baptista (1999), os amoladores de faca não entendem a vida em sua dimensão ética e coletiva. As falas dos amoladores de faca autorizam cortar membros das populações marginalizadas. Corpos e populações são cortadas e atravessadas por discursos que se dizem sem preconceitos - "essa é minha opinião", e que reproduzem com pedidos de desculpas -, discriminações e desigualdades. Se faz oportuno contextualizar a profusão de amoladores de facas durante as eleições presidenciais. Através das redes sociais ou nas ruas, as pessoas gritavam por volta da ditadura, morte aos gays, bandido bom é bandido morto, entre outras frases ditas em alto e bom tom. O cenário era constituído por "lapsos temporais", levando em consideração práticas como a caça às bruxas ou com pedidos de retorno a contextos ditatoriais.

\footnotetext{
${ }^{4} \mathrm{O}$ termo é em inglês, mas se tornou popular em todo o mundo para denominar informações falsas que são publicadas, principalmente, em redes sociais. Fonte: <https://mundoeducacao.bol.uol.com.br/curiosidades/fake-news.htm> Acesso em: 8 maio 2020.
} 
Diante do fascismo escancarado, a peça constitui-se como resistência aos tempos de ódio e ressentimento que o país estava retroalimentando. A tensão acirrada do governo do Michel Temer - com ações marcadas por sexismo, racismo, precarização da saúde, da educação e retirada de direitos - eram pano de fundo da aclamação dos discursos de ódio proferidos pelo candidato à presidência Jair Messias Bolsonaro. O candidato esbravejava falas como: "Nada tenho contra um gay" (28/08/2018); "Eu defendo a castração química para estupradores" (17/08/18); "[Trabalharemos pela] Redução da nossa maioridade penal, que é o que povo quer e deseja" (08/10/18), entre outras frases comentadas no site da Revista Piauís.

Nos esquetes da peça, as drags debochavam de nomes como de Magno Malta, Michel Temer, Aécio Neves, utilizando trechos de notícias para ironizar como esses políticos estavam envolvidos em casos de corrupção, tráfico de drogas, dentre outros assuntos. A trilha sonora do espetáculo era intercalada por reportagens jornalísticas e músicas brasileiras famosas. Como exemplo, para ironizar Magno Malta, as quatro drags utilizaram da música "As pirâmides de Faraó", de Aline Barros, que traz em sua letra: "Havia um rei lá no Egito chamado de Faraó. / Era um rei muito malvado esse tal de Faraó / Ôôôô sou um poderoso rei / Ôôôô todo esse povo escravizei / Ôôôô sou um poderoso rei / Ôôôô todo esse povo escravizei”. A ironização das drags, afetando-nos, nos remetia aos casos de corrupção envolvendo Magno Malta. ${ }^{6}$

O Festival Nacional de Teatro de Vitória apareceu para a aventureira através de divulgação de eventos no Facebook. O evento tinha o nome da peça, "Le Circo de La Drag", e em sua descrição anunciava que a peça abriria o festival contendo data, local e hora da apresentação. O espetáculo roda o Brasil, com alterações de roteiro de acordo com as regionalidades de cada lugar que visita. A peça, atenta

\footnotetext{
5 "Jair Bolsonaro eleito: veja aqui 110 frases ditas por ele e checadas pela Lupa em 2018". Disponível em: <https://piaui.folha.uol.com.br/lupa/2018/10/28/tudo-sobre-bolsonaro/> Acesso em: 18 maio 2020.

6 "Sanguessuga: PF indicia senador Magno <http://g1.globo.com/Noticias/Politica/0,,MUL31859-5601,00.html >; Troca de e-mails mostra que \begin{tabular}{lllllll}
\hline Magno Malta & recebeu & propina & & & mil
\end{tabular} <https://www.redebrasilatual.com.br/blogs/2016/08/troca-de-e-mails-mostra-que-magno-maltarecebeu-propina-de-r-100-mil-6476/ > Acesso em: 28 fev. 2020.
} 
aos últimos acontecimentos do país, cria estratégias políticas pela teatralidade como modo de denunciar desigualdades e afirmar reivindicações políticas.

\section{MONTAÇõES e suas implicações políticas}

Atenta à viagem que se fazia acontecer no palco daquele Teatro, afetada, discutiremos como as montações das drags do espetáculo foram percebidas pela viajante e pela amiga-viajante que também assistiu à peça. Iniciamos a conversa com as montagens ao perceber que as primeiras memórias da aventureira e da amiga-viajante foram como as montações da drags-atrizes se distanciavam do estereótipo construído, que supõe que as montagens necessariamente devem ter glamour, luxo, muitas cores, entre outros aspectos que as tornavam chamativas e estonteantes. Neste caso, estas drags-atrizes mostraram que existem outros modos de se constituir enquanto drags e os usos que elas fazem disso.

Em determinado momento da peça, a atenção da viajante se voltou para a composição das vestimentas das drags. Com colãs pretos e maquiagens com contornos acentuados, num estilo monocromático, estas drags não se montavam com glamour ou com indumentárias coloridas e/ou chamativas. Estas montagens tinham como pano de fundo um cenário que se assemelhava a um cabaré. Sem ornamentações estonteantes, o espetáculo foi construído por duas cores: preto e vermelho. (DIÁRIO DE CAMPO, 15/10/2018)

A atenção da aventureira foi perceber como as montagens das drags com roupas pretas e sem muito glamour destoam das drags queens que são midiatizadas, em filmes, séries, clipes de música. Como estamos falando de teatro, pensamos em como cada produção artística convoca montagens diferentes, considerando alcance/abrangência daquela produção, modos de divulgação, dentre outros aspectos. As produções das drags que participam de obras audiovisuais são atravessadas por interesses comerciais, padrões midiáticos, permeadas por alterações como filtros ou photoshop, ou seja, essas produções das drags são tecidas por interferências tecnológicas e por padrões estéticos do que é aceito na TV, em filme ou séries. Para nos ajudar nessa discussão, recorremos a Lucas Bragança, cuja dissertação intitulada Drag: mídia, corpo e afeto debateu como a mídia entende e fabrica as drag queens. De acordo com Bragança (2018), "podese afirmar, então, que a história drag também [foi] atrelada a uma cultura midiática interessada na exploração da 'cota de excentricidade' que a exibição desses corpos traz aos conteúdos televisivos" (BRAGANÇA, 2018, nota 68, p. 
77). Refletimos que essa "cota de excentricidade" solicita montações chamativas, consideradas "exóticas" e/ou extravagantes. Com isso, entendemos que o teatro não necessariamente está interessado em apresentar o excêntrico ou extravagante. No caso desta apresentação, pensamos que os processos de singularização daquelas montações estavam em diálogo com o cenário da peça, com as posturas políticas, as músicas, ou seja, como as montagens conversavam com o contexto apresentado no espetáculo. Para conversar com as singularidades daquelas drags, a viajante se pôs em conversa com uma amiga-viajante que também assistiu à peça. A aventureira pergunta à amiga-viajante como as drags tinham lhe afetado e a amiga-viajante diz que

O que me afetou das drags foi relacionado a um estereótipo que eu tinha formado a partir de questões coletivas de enunciação. Senti falta de mais, mais montagens. Me refiro a artefatos, das intervenções do corpo em si, estou falando de materialidade. Não sei por que, mas quando você me pergunta sobre o que me afetou, meu entendimento surge desse modo. De modo geral eles e elas estavam vestidas de preto. Senti falta de mais cores. Ao mesmo tempo, me leva a pensar que a intervenção era no luto, na dor, de uma questão mais de momento que estavam vivendo (DIÁRIO DE CAMPO, 10/11/2018)

A viajante e amiga-viajante dizem de como as montações daquelas drags lhe afetaram. Para a aventureira, aquela peça constitui-se com montagens que se distanciavam do que a amiga-viajante considerou como estereótipo. Sabemos que o estereótipo é construído por condições culturais, midiáticas, instituições sociais, políticas. Neste caso, a amiga-viajante afirma que o estereótipo é constituído por "questões coletivas de enunciação". Segundo Guattari e Rolnik,

A subjetividade é produzida por agenciamentos de enunciação. Os processos de subjetivação, de semiotização - ou seja, toda a produção de sentido, de eficiência semiótica - não são centrados em agentes individuais (no funcionamento de instâncias intrapsíquicas, egoicas, microssociais), nem em agentes grupais. Esses processos são duplamente descentrados. Implicam o funcionamento de máquinas de expressão que podem ser tanto de natureza extrapessoal, extraindividual (sistemas maquínicos, econômicos, sociais, tecnológicos, icônicos, ecológicos, etológicos, de mídia, enfim sistemas que não são mais imediatamente antropológicos), quanto de natureza infra-humana, infrapsíquica, infrapessoal (sistemas de percepção, de sensibilidade, de afeto, de representação, de imagens, de valor, modos de memorização e produção de ideia, sistemas de inibição e de automatismos, sistemas corporais, orgânicos, biológicos, fisiológicos, etc.). (GUATTARI E ROLNIK, 1999. p. 31)

Cadernos de estudos culturais, Campo Grande, MS, v. 2, p. 9-23, jul./dez. 2020. 
Ponderamos que os agenciamentos de enunciação produzem alguns sentidos que atribuímos às drag queens, ou seja, somos atravessados pela "natureza extrapessoal". Nessa direção, podemos dizer que a força da mídia apresenta drag queens glamorosas ou "mais coloridas". Com Guattari e Rolnik (1999), compreendemos também que somos permeados pela dimensão "infrapsíquica", ou seja, pelos afetos. Nessa aventura, estamos afetados pelos sentidos produzidos com as experiências singulares das drag queens. A amiga-viajante percebeu que o "sentir falta de mais cores e artefatos" está interligado com uma construção estereotipada da drag queen. Ao analisar o contexto brasileiro e os temas trazidos pela peça, a amiga-viajante considera que as roupas pretas fazem alusão a dor e luto diante aos discursos de ódio e acirramento de ideias durante as eleições presidenciais. Para esta amiga-viajante, as montagens conversavam com as problemáticas levantadas na peça formando pontos e interseções entre as montações, os cenários, as problematizações, as músicas, as notícias, entre outros elementos.

A amiga-viajante também comenta que "não [sei] por que, mas quando você me pergunta sobre o que me afetou, meu entendimento surge desse modo". Esse trecho da conversa com a amiga-viajante nos mostra como suas impressões sobre a peça foram tecidas com as intervenções e ponderações da aventureira. Entendemos que, "em certos casos, nos diz o pesquisador, o deslizamento do olhar do entrevistado pode indicar uma mudança de direção da atenção do mundo exterior rumo ao próprio processo da experiência" (TEDESCO, SADE, CALIMAN, 2013, p. 305). O olhar da amiga-viajante alterou a experiência que a viajante construiu assistindo à peça:

Acho interessante você falar isso porque não eram montagens glamorosas. Parecia ser uma montação mais simples, mais restrita, para afirmar um contexto político da situação. A peça é muito politizada, constantemente fazia referências ao contexto político que estávamos vivenciando (DIÁRIO DE CAMPO, 15/10/2018)

A viajante e a amiga-viajante começaram a pensar sobre as implicações políticas e estéticas daquela apresentação. Para viajantes da mesma cena, aquelas montagens eram simbólicas e pertinentes ao enredo do espetáculo. Os entendimentos da viajante e de sua amiga se aproximam da discussão de Rodrigo Carvalho Marques Dourado, no livro Bonecas falando para o mundo: identidades 
sexuais "desviantes" e teatro contemporâneo ${ }^{7}$. No texto, esse viajante faz uma leitura como Judith Butler entende performance e teatro: "nesse sentido, a autora [Judith Butler] vê no teatro um grande potencial de exposição dos 'comportamentos sociais' como já performativos e uma possibilidade de desnaturalização dos mesmos" (DOURADO, 2017, p. 165). Segundo ele, o teatro acontece como possibilidade de desnaturalizar as convenções sociais e políticas em que estamos inseridos. As drags da peça desnaturalizaram o estereótipo da constituição da drag queen e da construção da realidade. Minha companheira da experiência teatro, conversante nesse translado, além de analisar como as montações conversam com a proposta do espetáculo, acrescenta que as montações das drags "rompem o pensamento". Segundo ela, as drags convocam descolamentos e rupturas nos pensamentos.

Fico pensando nisso agora junto com você. Será que é um estereótipo meu sobre como é a questão dos artefatos que elas usam? A utilização das roupas pretas se faz como conteúdo semântico. Rompe e violenta o pensamento, manifestando artisticamente essa intervenção no corpo. Penso contigo o momento político que a gente está vivendo e considero que no mês das eleições nós estávamos muito sensibilizadas com tudo que estava acontecendo. A gente precisava desse tipo de coisa, de romper o pensamento e o fazer funcionar de outro jeito (DIÁRIO DE CAMPO, 10/11/2018).

De acordo com a amiga-viajante, as montagens formam um "conteúdo semântico que rompem com o pensamento", ou seja, nos descola e faz com que o nosso corpo "funcione de um outro jeito". Recorremos a Deleuze (1992) ao compreender que "pensar é sempre experimentar, não interpretar, mas experimentar, e experimentação é sempre o atual, o nascente, o novo, o que está em vias de se fazer" (DELEUZE, 1992, p. 136). Romper o pensamento convoca a experimentação. Com o rompimento é possível transmutar os processos de subjetivação que nos constituem. Para a interlocutora, a ruptura do pensamento feita pelas drags se fez necessária naquele momento, para segundo ela "funcionar de outro jeito". O deslocamento produz desvios na lógica, nos hábitos, no

7 “[O livro] trata das relações entre o teatro contemporâneo e as identidades sexuais 'desviantes'. Tendo como objetos de análise os espetáculos Carnes Tolendas: retrato escénico de un travesti (ARG), Luis Antonio-Gabriela (BR), Ópera (BR) e Paloma para matar (BR), seu objetivo é investigar como as formas assumidas pela cena na atualidade traduzem uma crise das categorias identitárias, que se reflete nas representações das experiências sexuais fora da norma" (DOURADO, 2017). 
contínuo. Concordamos com a amiga-viajante que romper o pensamento se faz necessário para permitir que nossos corpos se tornem porosos/abertos aos afetos. A aventureira interveio solicitando que a amiga-viajante aprofundasse sobre o que ela considera como rompimento produzido pelas drags:

Elas [as drags] vão além. No momento que elas se montam, no momento que produzem outro corpo, dá para perceber as trocas e como que elas desafiam aquilo que a gente tem entendido como gênero, como sexualidade. Me refiro também à academia. Ao ir além, obriga a gente a criar outros modos de nos colocar na troca. Não só na performance em si, no trânsito delas, pela rua, pela universidade, na calçada. Quando falo em romper me refiro um pouco a isso, que elas quebram o entendido pela sensibilidade. Não é a racionalidade da academia que vai explicar. Vai pelas afetações pensar no que uma drag faz através da arte que elas produzem, da intervenção do corpo e na performance e refletir como a drag faz com as produções sobre gênero e sexualidade (DIÁRIO DE CAMPO, 10/11/2018)

Ponderamos que a compreensão de que a drag desafia os entendimentos acerca de gênero e sexualidade conversa com a concepção da aventureira e do amigo-viajante que apresentamos no quarto translado desta dissertação. Os três percebem que a drag vai além de uma racionalidade, do pragmatismo das produções de saber acerca de gênero, corpo, sexualidade, sexo, dentre outros temas. Com isso esta pesquisa se propõe a produzir conhecimentos que afirmem a potência dos afetos. Assim, o que nos interessa é como os afetos nos movem e o que fazemos com eles. Ao falar da academia, a amiga-viajante convoca a viajante a melhor compreender que "acessar essa dimensão movente do real implica acessar as condições de emergência dos objetos, o que viabiliza intervir, fazer variar e atualizar outras realidades" (BARROS e HEBERT, 2013, p. 347).

\section{RISO, paródia e deboche}

Voltemo-nos neste momento para as paródias produzidas pelas drags na encenação. O espetáculo utilizou do deboche, ironia e ousadia como estratégias para conquistar o público e zombar dele ao mesmo tempo. Usaram de recursos musicais, corporais para criarem as sátiras e, por esta via, as drags ridicularizaram atos banais com uma crítica política consistente. Recorremos a Djalma Thürler (2017), viajante que se ocupa com o teatro, com o pensamento sensível e com o corpo em cena, para nos ajudar a pensar como o teatro constitui nossos modos de vida. Segundo esse viajante, "o teatro amplia nossas possibilidades, muda nossos 
nomes, embaralhando, se perdendo, se confundindo. Em cena, 'Elas-eles' ou 'eles-elas' parecem não pretender ser qualquer coisa, apenas escapar, libertar-se da sociedade-casa-prisão" (THÜRLER et al, 2017, p. 171).

As possibilidades de satirizar nossas realidades são usadas no teatro como modo de provocar desconforto e incômodos na sociedade. O teatro aconteceu como ação propositiva e, nessa ação, experimentarmos e refletirmos o que estamos fazendo de nós mesmos. A aventureira exposta na cena percebe como a ironia é artisticamente utilizada para convocar afirmações políticas na população:

A ironia de como a política vai pregando peças é teatralizada pelas $d r a g s$, ora usando bananas, cartazes irônicos, máscaras com rostos de políticos, gargalhadas e muita criatividade. A comicidade de assuntos importantes e polêmicos beira a convocar como nos posicionamos aos acontecimentos mais emblemáticos que estamos vivenciando no Brasil. (DIÁRIO DE CAMPO, 15/10/2018)

A peça convocou a problematizarmos, nessa viagem pelo meio, como estamos vivendo. $\mathrm{O}$ teatro nos oferece outros modos de perceber a produção e os efeitos de realidade. Dourado (2017, p. 167) entende que a peça teatral "trata-se, portanto, de uma recriação político-paródica, alegórica, hiperbólica, metafórica do real, que preserva alguma semelhança com ele, mas cujo enquadramento artístico serve para indagá-lo nas verdades estabelecidas, expondo-lhe os arranjos e mecanismos de composição". A peça "Le Circo de La Drag" apresentou como músicas consagradas e cantadas por multidões por anos "escondem" preconceitos e discriminações, reforçam estereótipos e violentam determinadas populações. A peça nos convida a pensar nos detalhes dos nossos cotidianos, do que escutamos, assistimos, presenciamos, traz em seus esquetes reflexões sobre como músicas, notícias, contextos reproduzem violências, e nós não percebemos essas perpetuações da violência. Assim, o teatro tem como potência fazer repensar nosso atos, posições e pensamentos. O espetáculo convoca debates que envolvem discutir nossas responsabilidades sobre os contextos em que estamos inseridos, trazendo em cada esquete reflexões sobre como atuamos na esfera política, ética, social e cultural. Pensamos com Thürler (2017) que, quando a arte dramática suscita repensar e reivindicar a legitimidade de como nos relacionamos, vivemos e percebemos o mundo, ela garante o exercício da liberdade do corpo como exercício político. Para o autor,

A arte dramática, quando garante a liberdade de fala, quando a significa diante do seu poder, de algum modo desafiador, ensaia a busca da legitimidade aos direitos ao corpo, ao gênero, à raça, aos desejos, às diversidades sexuais, ao poder de

Cadernos de estudos culturais, Campo Grande, MS, v. 2, p. 9-23, jul./dez. 2020. 
diferenciar-se do instituído e exercer o estado de ser diferente (THÜRLER, 2017, p. 51).

É na feitura da diferença que somos convocados a perceber como nossas práticas podem escrever outras histórias. A arte dramática encenada por essas drags nos agita e desloca para compreendermos as capturas às quais estamos submetidos e como lidamos com elas. Diante de uma parcela da população que em coro pede o retorno da ditadura (época marca pela censura das apresentações artísticas), a peça "Le Circo de La Drag" vive em um campo minado de desqualificação das obras artísticas. Rolnik (2018, p. 167) afirma que o ataque é destinado a "certas práticas artísticas - as que trazem à tona questões de gênero, de sexualidade e de religião - [que] passam a ser desqualificadas, perseguidas e criminalizadas". Inserida nesta produção de desqualificação e censuras de movimentos artísticos com críticas políticas, sobre gênero e sexualidade, as drags da peça zombam e trazem reflexões sobre o que estávamos vivendo.

Para continuar conversando sobre os afetos dos encontros com as drags deste espetáculo, nos colocamos em conversa com o mesmo amigo-viajante que participou do evento sobre Cultura Drag e também assistiu à peça "Le Circo de La Drag”. Ele relata:

Fui do riso ao choro. Foi genial o deboche que eles fizeram com o Magno Malta. Aquela música gospel de fundo, delicioso aquilo. Achei muito legal quando pisaram no retrato do Temer e ergueram o retrato da Marielle ${ }^{8}$, homenageando ela, fiquei muito emocionado nessa parte sabe. Eu achei que foi uma peça incrível de humor, deboche, politizada ao mesmo tempo de resistência (DIÁRIO DE CAMPO, 16/11/2018)

O amigo-viajante destaca a existência do humor e do riso na peça. Segundo ele, o humor e o deboche foram combinados com um modo politizado de fazer resistência diante da realidade brasileira. Os afetos que foram constituídos com a peça possibilitaram pensar que podemos produzir torções nos comportamentos. Ou seja, criar outros possíveis cenários que subvertem os acontecimentos em que estamos inseridos. Nesse caso o espetáculo utilizou do humor e da ironia como insubordinação a práticas retrógradas. O amigo-viajante informa que a peça lhe

\footnotetext{
8 Marielle Franco, vereadora do Rio de Janeiro, e seu motorista Anderson Gomes foram assassinados com sete tiros no dia 14 de Março de 2018. O grito "Quem mandou matar Marielle e Anderson?" ecoa dois anos após as mortes.
} 
proporcionou riso e choro. O riso no teatro é discutido por Dourado (2017). Para ele, é preciso perceber como "o debate sobre o riso e a comicidade a fim de enxergar como o espetáculo problematiza as questões do corpo, da natureza e da cultura nas representações do desviante" (DOURADO, 2017, p. 35). A comicidade apresentada como sátiras políticas pelas drags no espetáculo carrega problematizações que debatem questões como feminismo, racismo, homofobia, classismo, entre outros assuntos. Ou seja, a comicidade é um modo político de incitar reflexões sobre problemáticas sociais, culturais e políticas. Retomemos a amiga-viajante, com a qual nos colocamos em conversa no início deste translado e que também relata como se afetou assistindo à peça:

Chorei, ri, acho que é importante não perder a alegria. Mesmo naqueles momentos quando abate o cansaço, não podemos deixar que nos roubem a nossa alegria. Podemos pensar como a gente cria outros modos de ocupar, de resistir, porque acho que as drags ensinam através da arte outros modos de resistir e ocupar. Para mim as drags intervêm, por outras sensibilidades, que fogem, rompem e que obrigam a produzir outras formas. (DIÁRIO DE CAMPO, 10/11/2018)

Ponderamos junto desta amiga-viajante a potência de criar outros modos de ocupar e resistir. Para ela, as intervenções das drags feitas através da arte são convites para criação, para inventividade de lidar com os momentos que vivemos. Pensamos em traçar estratégias para a permanência de debates, trocas, intervenções e outras ações que estão sendo colocadas à prova pelas configurações políticas. Durante as eleições, espaços de debates políticos e filosóficos sofreram censuras e perseguições, dentro de Universidades, praças, dentre outros lugares, desmantelando exercícios democráticos ${ }^{9}$. Diante dessas perseguições e precarização da democracia, a amiga-viajante explica que tem momentos em que "abate o cansaço". Isso ocorre quando o corpo diminuiu a vibração, quando ficamos "em coma" e o cansaço acaba falando mais alto do que a potência inventiva. Recorremos a Rolnik (2003) para entender essa potência inventiva:

\footnotetext{
${ }^{9}$ Relatório denuncia perseguição a acadêmicos e universidades no mundo, com destaque inédito no Brasil. Disponível em: 〈https://www.bbc.com/portuguese/geral-50695248> Acesso em: 19 jun. 2019.

Às vésperas do segundo turno, universidades são alvo de perseguição política pelo país. Disponível em: <http://www.justificando.com/2018/10/26/as-vesperas-do-segundo-turnouniversidades-sao-alvo-de-perseguicao-politica-pelo-pais/> Acesso em: 19 jun. 2019.
} 
Do lado da potência de invenção, é o acesso ao corpo vibrátil que orienta seu exercício de modo a dar consistência existencial ao processo de emancipação que se faz necessário, se entendermos a arte como o exercício de rastreamento das mutações que se operam nas sensações, as quais indicam o que está pedindo um novo sentido, novos recortes e novas regras, orientando assim o ato de sua criação. (ROLNIK, 2003, p. 4)

Com isso compreendemos que essas drag-atrizes nos convocam a pensar novos sentidos e recortes para nossa vida. Com elas, podemos repensar nossas alianças, acordos e ações. Em nossos processos inventivos, somos levados a expandir nossa energia vital, ou seja, esses processos acontecem quando apostamos em práticas prudentes e éticas. Em nossas viagens com as drags, participando de uma mesa de debate, performando na Universidade ou atuando no teatro, somos impelidos a apreender com elas como ocupar os espaços de diferentes modos. A diferença das drags nos convida a romper e ruir os modos de vida que enclausuram nossa energia vital, mostrando que podemos nos expressar e resistir através da arte.

A compreensão da peça como um modo de resistência também foi percebida pelo amigo-viajante. Ele afirma que foi a primeira vez que assistiu a um espetáculo politizado que convocou posicionamos na plateia. Pensamos que as pessoas presentes naquele momento endossaram posicionamentos éticos e coletivos, entendendo a importância da dimensão coletiva de nossas ações.

Além das partes que me fizeram rir e chorar, teve uma parte que naquela fase das eleições presidenciais, que eles começaram a fazer as performances políticas no palco e a plateia começou a gritar "ele não", e não foi um chamado dos atores da peça. A plateia foi tomada pelo potencial político do espetáculo. Eles mesmos começaram a gritar "ele não, ele não", em contraposição à campanha do Bolsonaro. Muito bonita aquela energia, aquelas pessoas todas ali afinadas com o mesmo propósito. Foi fantástico, foi uma experiência realmente incrível, foi a primeira vez que eu participei de uma peça de teatro com esse teor político. (DIÁRIO DE CAMPO, 16/11/2018)

Produções de paródias no mês das eleições de 2018, marcado pelas polarizações e pelo acirramento de vínculos familiares ou de amizade, a peça se fez ousada e atrevida, utilizou das feridas abertas das crises do país e convocou o público a sentir, pensar e vivenciar de outros modos naquele mês tão tumultuado. A resistência dessa peça aconteceu como repúdio a qualquer tipo de incitação ao ódio, contra os discursos dos amoladores de faca. A peça resistiu ao projeto de nação que marginaliza e ignora algumas existências, mulheres, idosos, crianças, 
indígenas, LGBT's, entre outros grupos que foram e estão sendo atacados em várias dimensões por posturas políticas que procuram deslegitimar esses modos de vida.

\section{REFERÊNCIAS BIBLIOGRÁFICAS}

BARROS, Maria Elizabeth Barros de; SILVA, Fabio Hebert da. O trabalho do cartógrafo do ponto de vista da atividade. Fractal, Rev. Psicol., Rio de Janeiro, v. 25, n. 2, p. 339355, Aug. 2013. Disponível em:

<http://www.scielo.br/scielo.php?script=sci_arttext\&pid=S198402922013000200008\&lng=en\&nrm=iso >.Acesso em: 11 nov. 2018.

BRAGANÇA, Lucas. Desaquendando a história Drag: no mundo, no Brasil e no Espírito Santo. Vitória: Edição Independente, 2018.

DELEUZE, Gilles. Conversações. Trad. Peter Pál Pelbart. Rio de Janeiro: Editora 34, 1992.

DOURADO, Rodrigo. Bonecas falando para o mundo: Identidades "desviantes" de gênero e sexualidade no teatro. São Paulo: Sesc, 2018.

GUATTARI, Felix; ROLNIK, Suely. Micropolítica. Cartografia do Desejo. Petrópolis: Vozes, 1999.

ROLNIK, Suely. Esferas da Insurreição.São Paulo: N-1 edições, 2018.

ROLNIK, Suely. Geopolítica da cafetinagem. 2006. Disponível em: http://www.pucsp. br/nucleodesubjetividade. Acesso em: 20 jan. 2020.

TEDESCO, Silvia; SADE, Cristão; Caliman, Luciana Vieira. A Entrevista na pesquisa cartográfica: a experiência do dizer. Fractal, Rev. Psicol. Rio de Janeiro, v. 25, no 2, p. 299-322, Agosto de 2013.

Disponível

em:

$<$ https://www.scielo.br/scielo.php?script=sci_arttext\&pid=S1984-

02922013000200006\&lng=en\&nrm=iso> Acesso em: 11 nov.2018.

THÜRLER, Djalma; WOYDA, Duda; MEDRADO, Rafael; LOBO, Marcus. Dramaturgias Voadoras. Bahia: Editora Devires, 2017.

\section{SITES}

ALVIM, Mariana. Relatório denuncia perseguição a acadêmicos e universidades no mundo, com destaque inédito ao Brasil. BCC, São Paulo, 10/12/2019. Disponível em: <https://www.bbc.com/portuguese/geral-50695248\#_blank >. Acesso em: 10 jul. 2019. 
EQUIPE LUPA. Jair Bolsonaro eleito: veja aqui 110 frases ditas por ele e checadas pela Lupa em 2018. Revista Piaú, Rio de Janeiro, 28/11/2018. Disponível em: <https://piaui.folha.uol.com.br/lupa/2018/10/28/tudo-sobre-bolsonaro/>. Acesso em: 10 jul. 2019.

Fake news. Disponível em: <https://mundoeducacao.bol.uol.com.br/curiosidades/fakenews.htm>. Acesso em: 10 dez. 2018.

Perfil do grupo Le Circo de La Drag. Disponível em: <https://prosas.com.br/empreendedores/18463?locale=en> Acesso em: 10 dez. 2018.

PRADO, Gabriel. Às vésperas do segundo turno, universidades são alvo de perseguição política pelo país. Justificando, 26/10/2018. Disponível em: <http://www.justificando.com/2018/10/26/as-vesperas-do-segundo-turno-universidadessao-alvo-de-perseguicao-politica-pelo-pais/ >. Acesso em: 10 jul. 2019.

Sanguessuga: PF indicia Senador Magno Malta. G1, São Paulo, 05/05/2007. Disponível em: <http://g1.globo.com/Noticias/Politica/0,,MUL31859-5601,00.html>. Acesso em: 12 jul. 2019

STHEPHANOWITZ, Helena. Troca de e-mails mostra que Magno Malta recebeu propina de R\$ 100 mil. Rede Brasil Atual, São Paulo, 15/08/2016. Disponível: <https://www.redebrasilatual.com.br/blogs/2016/08/troca-de-e-mails-mostra-que-magnomalta-recebeu-propina-de-r-100-mil-6476/>. Acesso em: 14 jul. 2019.

Artigo recebido em: 30 de setembro de 2020 . Artigo Aprovado em: 18 de dezembro de 2020. 
